Fibrinogen Maracaibo: Hypo-Dysfibrinogenemia Caused by a Heterozygous Mutation in the Gen that Encodes for the Fibrinogen A $\alpha$ Chain (G.1194G>A: P.Gly13>Glu) with Diminished Thrombin Generation

\title{
Marchi $\mathbf{R}^{1 *}$, Rojas $\mathbf{H}^{2}$, Echenagucia $\mathbf{M}^{3}$, Meyer $\mathbf{M}^{4}$, Acosta $\mathbf{M}^{5}$, $A$ pitz $\mathbf{R}^{3}$ and Ruiz-Sáez $\mathrm{A}^{3}$
}

${ }^{1}$ Centro de Medicina Experimental, IVIC, Caracas, República Bolivariana de Venezuela

${ }^{2}$ Instituto de Inmunología, Universidad Central de Venezuela. República Bolivariana de Venezuela

${ }^{3} \mathrm{CNH}$-Banco Municipal de Sangre, DC, República Bolivariana de Venezuela

${ }^{4}$ University of Applied Sciences, Department of Medical Engineering and Biotechnology, Jena, Germany

${ }^{5}$ Banco de Sangre del Estado Zulia. República Bolivariana de Venezuela

\begin{abstract}
Introduction: Hereditary fibrinogen abnormalities can be quantitative and/or qualitative. In hypofibrinogenemia and hypodysfibrinogenemia fibrinogen levels are below $150 \mathrm{mg} / \mathrm{dL}$.
\end{abstract}

Objectives: The aim of the present work was to characterize the fibrinogen abnormalities in a family where the propositus (an asymptomatic four-year-old male) and his mother had prolonged thrombin time and low fibrinogen levels.

Methods: Fibrinogen genes were sequenced. Preliminary studies were performed on fibrin (ogen) function and fibrin network characteristics. Fibrin formation kinetic was done in plasma and purified fibrinogen. Fibrin network porosity was measured and fibrin structure visualized by laser scanning confocal microscopy (LSCM). In addition, global haemostatic tests such as thrombin generation and thromboelastography were performed.

Results: DNA analysis revealed a heterozygous mutation in the fibrinogen gen that encoded for the $A \alpha$ chain (FGA g.1194G>A: p.Gly13>Glu) in the propositus and his mother. In plasma and purified fibrinogen, the rate of patients' fibrin formation was approximately two times slower compared to control. Propositus' fibrin porosity was similar to control, but diminished in his mother $(\mathrm{p}<0.05)$. By LSCM patients' clots morphology were similar to control. Thromboelastographic study was normal in both patients, and thrombin generation diminished in the propositus.

Conclusions: The mutation of fibrinogen at Aa Gly13>Glu impairs fibrin polymerization. The differences found in thrombin generation between the propositus and his mother highlights the utility of global assays for therapy individualization.

Keywords: Hypo-dysfibrinogenemia; Fibrin kinetic; Fibrin structure; Thrombin generation; Thromboelastography

\section{Introduction}

Fibrinogen or coagulation factor I (FI) is a glycoprotein of $340 \mathrm{k}$ Da present in plasma at $2-4 \mathrm{mg} / \mathrm{mL}$, is synthesized predominantly in the liver and its levels increase under inflammatory stimuli $[1,2]$. Fibrinogen is secreted into the bloodstream as a hexamer composed by three pairs of identical chains $(\mathrm{A} \alpha, \mathrm{B} \beta$ and $\gamma) 2$, joined together by 29 disulphide bonds that form a dimer. Each fibrinogen chain is encoded by paralogous genes (FGA, FGB, and FGG for $A \alpha, B \beta$ and $\gamma$ chains, respectively) [3]. In the last step of the coagulation cascade, thrombin cleaves the bonds at A $\alpha$-Arg16 and B $\beta$-Arg14 removing short electronegative peptides (fibrinopeptides A and B, respectively). These modified fibrinogen molecules (fibrin monomers) polymerize spontaneously and form the 3-dimentional clot network that is further stabilized by activated factor XIII (FXIIIa) [4].

Inherited fibrinogen disorders affect either the quantity (hypofibrinogenemia, fibrinogen levels $<150 \mathrm{mg} / \mathrm{dL}$ ) and afibrinogenemia, characterized by the complete deficiency of fibrinogen or the quality of the circulating fibrinogen (dysfibrinogenemia) or both (hypo-dysfibrinogenemia) [5]. Up to date, approximately 115 mutations have been reported that cause dysfibrinogenemia, 67 hypofibrinogenemia, 75 afibrinogenemia, and 13 hypodysfibrinogenemia; 101 in the $A \alpha, 63$ in the $B \beta$ and 93 in the $\gamma$ chain. About $50 \%$ of approximately more than 600 cases reported in the literature are silent [6,7]. Thrombin binds to its substrate, fibrinogen, and remains bound to the product, fibrin, after fibrinopeptides are removed [8,9]. Different studies have established that Asp7 to Val20, particularly residues on the $\mathrm{N}$-terminal side $\mathrm{P} 1$ to $\mathrm{P} 10$ (nomenclature is that suggested by Abramovitz [10]) are required for the binding of fibrinogen's fibrinopeptides to thrombin [11]. Within the sequence of fibrinopeptide $\mathrm{A}$ there are both critical (nonvariable) residues and those that can be modified without impairs thrombin catalytic activity [12]. The amino acid sequence of FpA between Asp7 and Arg16 is highly conserved among mammalian species, suggesting that this region is critical for thrombin binding $[13,14]$. Several abnormal fibrinogens

*Corresponding author: Rita Marchi Cappelletti. Centro de Medicina Experimental, Laboratorio de Fisiopatología, Sección Biología del Desarrollo de la Hemostasia. Instituto Venezolano de Investigaciones Científicas, IVIC. Apartado 20632, Caracas 1020-A, República Bolivariana de Venezuela. Tel. +58-212 5041526 Fax: +58-212-5041086. E-mail: rmarchi@ivic.gob.ve

Received March 10, 2014; Accepted April 26, 2014; Published May 05, 2014

Citation: Marchi R, Rojas H, Echenagucia M, Meyer M, Acosta M, et al. (2014) Fibrinogen Maracaibo: Hypo-Dysfibrinogenemia Caused by a Heterozygous Mutation in the Gen that Encodes for the Fibrinogen Aa Chain (G.1194G>A P.Gly13>Glu) with Diminished Thrombin Generation. J Blood Disorders Transf 5 : 215. doi: $10.4172 / 2155-9864.1000215$

Copyright: ( 2014 Marchi R, et al. This is an open-access article distributed unde the terms of the Creative Commons Attribution License, which permits unrestricted use, distribution, and reproduction in any medium, provided the original author and source are credited. 
Citation: Marchi R, Rojas H, Echenagucia M, Meyer M, Acosta M, et al. (2014) Fibrinogen Maracaibo: Hypo-Dysfibrinogenemia Caused by a Heterozygous Mutation in the Gen that Encodes for the Fibrinogen Aa Chain (G.1194G>A: P.Gly13>Glu) with Diminished Thrombin Generation. J Blood Disorders Transf 5: 215. doi: 10.4172/2155-9864.1000215

Page 2 of 5

have been reported with mutations in this region: Asp7>Asn [15], Phe8 $>$ Cys [6], Leu9 $>$ Pro [16], Glu11 $>$ Gly [17], Gly12>Val, and Gly13>Glu in fibrinogen Olovnice [18] and Krakow II [19].

Fibrinogen Maracaibo is a new venezuelan abnormal fibrinogen with an asymptomatic phenotype discovered during preoperative examination in a four-year-old boy. The A $\alpha$ Gly13>Glu delayed fibrin formation; however, normal clot morphology was observed.

\section{Methods}

\section{Blood collection and routine coagulation tests}

Blood was collected in citrate ( 1 volume of $0.13 \mathrm{~mol} / \mathrm{l}$ trisodium citrate and 9 volumes of blood) and immediately centrifuged at $2500 \times$ $\mathrm{g}$ and $4^{\circ} \mathrm{C}$, during $20 \mathrm{~min}$. Plasma was aliquoted and kept frozen until use. Routine coagulation tests were performed with citrated plasma on coagulation analyzer STA Compact ${ }^{\circledR}$, Stago, France. Fibrinogen level was determined by Clauss (Laboratoire Stago, Asnière, France) and clot weight method [20].

\section{Mutation analysis}

Genomic DNA was isolated using the Invisorb Spin Blood Mini Kit (Invitek GmbH, Berlin, and Germany) according to the manufacturer's protocol. Sequences comprising all exons and exonintron boundaries from the three fibrinogen genes: FGA, FGB, and FGG were amplified by the polymerase chain reaction (PCR) according to standard protocols. After purification of the PCR products using the Invisorb Spin PCRapid Kit ${ }^{\circledR}$ (Invitek, Berlin, FRG), direct DNA cycle sequencing was performed, applying the Big Dye kit from Applied Biosystems (Foster City, CA, USA), according to the manufacturer's recommendations.

\section{Fibrin network characterization}

Fibrin polymerization: Fibrin polymerization was examined in plasma and purified fibrinogen. One hundred $\mu \mathrm{L}$ of plasma was mixed with $10 \mu \mathrm{L}$ of bovine thrombin $-\mathrm{CaCl}_{2}$ solution $(0.6$ units $/ \mathrm{mL}$ and $20 \mathrm{mM}$, final, respectively); samples were run by triplicate. Purified fibrinogen (obtained by $\beta$-alanine precipitation [21]) at $1 \mathrm{mg} / \mathrm{mL}$ in Tris - buffered saline ( $50 \mathrm{mM}$ Tris, $0.15 \mathrm{M} \mathrm{NaCl}$ ), $\mathrm{pH} 7.4$ was incubated for 1 min with $5 \mathrm{mM}$ of $\mathrm{CaCl}_{2}$ (final concentration), then clotted with 1 units/mL of thrombin (final concentration); samples were run by triplicate in three independent experiments. Changes in absorbance were followed during $1 \mathrm{~h}$ every $15 \mathrm{sec}$ at $37^{\circ} \mathrm{C}$ in a Tecan Infinite M200 microplate reader (Vienna, Austria). The lag time, slope and maximum absorbance (MaxAbs) were calculated for each curve and averaged.

Permeation: Permeation through plasma clots was performed essentially as described elsewhere [22]. The clotting conditions used were $0.6 \mathrm{unit} / \mathrm{mL}$ of thrombin and $20 \mathrm{mM} \mathrm{CaCl}$ (final concentrations). The buffer percolated through the column was Tris-buffered saline (50 $\mathrm{mM}$ Tris, $0.15 \mathrm{M} \mathrm{NaCl}, \mathrm{pH}$ 7.4). In general, six clots were used and one measurement of each was taken. Experiments were done by triplicate except for the propositus where only 7 clots were run due to the scarcity of his plasma.

The permeation coefficient or Darcy constant (Ks) was calculated using the following equation [23]:

\section{$\mathrm{Ks}=\mathrm{QL} \eta / \mathrm{tAP}$}

Where $\mathrm{Q}=$ volume of the buffer $\left(\mathrm{cm}^{3}\right)$, having a viscosity $\eta$ (poise), flowing through a column of height $\mathrm{L}(\mathrm{cm})$ and area $\mathrm{A}\left(\mathrm{cm}^{2}\right)$ in a given time $(\mathrm{sec})$, under a hydrostatic pressure $\mathrm{P}\left(\right.$ dyne $\left./ \mathrm{cm}^{2}\right)$.
Laser scanning confocal microscopy of fibrin clot: Fibrin clots were formed inside the eight wells LabTek chambers (Invitrogen, Nalge Nunc International, Rochester, NY, USA). The plasma sample was mixed with Alexa Fluor 488-labeled fibrinogen $(4 \mu \mathrm{g} / 215 \mu \mathrm{l}$ final sample volume), then clotted with a thrombin - $\mathrm{CaCl}_{2}$ solution $(0.14$ $\mathrm{U} / \mathrm{mL}$ and $19 \mathrm{mM}$, respectively, final concentration). The chambers were placed in a moist environment for $2 \mathrm{~h}$ at $37^{\circ} \mathrm{C}$ for complete fibrin polymerization. The fibrin clots were observed in an Olympus laser scanning confocal microscopy (LSCM) system, Model FV1000, with an argon ion laser (473 $\mathrm{nm}$ excitation and 520/540 $\mathrm{nm}$ for emission). The objective used was UPLSAPO 60X W NA: 1.20 water immersions with a work distance of 0.28 . The acquisition pinhole was set to $100 \mu \mathrm{m}$. The images were acquired with a field of view of $212 \times 212 \mu \mathrm{m}(0.331 \mu \mathrm{m} /$ pixel). One $\mathrm{z}$-stack of $30 \mu \mathrm{m}$ thick $(1 \mu \mathrm{m} / \mathrm{slice})$ and one volume render was made for each field. Image analysis was performed as described elsewhere [24].

\section{Haemostasis global tests}

Thromboelastography: The extrinsic (PT-Fibrinogen Recombinant, HemosIL, Instrumentation Laboratory) and the intrinsic (APTT-SP, HemosIL, Instrumentation Laboratory) blood coagulation pathway were evaluated by thromboelastography in a ROTEM $^{\circledR}$ instrument (Pentapharm, Germany). The parameters of clot time (CT), rate of clot formation (CFT), maximum clot firmness (MCF), alpha angle ( $\alpha$ ), maximum lysis (ML), and amplitude at 10,15 and 20 min were calculated. Patients' samples were run by duplicate and values averaged.

Calibrated Automated Thrombin Generation (CAT): Thrombin generation in plasma was measured by calibrated automated thrombography (CAT). Plasma was prepared by centrifuging twice at $2900 \times \mathrm{g}$ for $10 \mathrm{~min}$ at room temperature, essentially as described elsewhere [25]. Reactions were triggered with $1 \mathrm{pM} \mathrm{TF} / 4 \mu \mathrm{M}$ lipid in a Fluoroskan Ascent fluorometer (TermoLabsystem, Helsinki, Finland). Thrombin generation parameters were calculated using Thrombinoscope software version 3.0.0.29 (Thrombinoscope BV, Maastricht, Netherlands).

\section{Statistical Analysis}

The data obtained from the different assays are represented as the mean \pm standard deviation (SD). Statistical analysis was done using Origin Pro version 8.1. Purified fibrinogen polymerization, Ks, and LSCM results were compared using the Student's t-test and a $p<0.05$ was considered statistically significant.

\section{Results}

\section{Case report}

A four-year-old boy was referred to the Banco Municipal de Sangre of Caracas due to low functional fibrinogen levels, found during preoperative examination for hernia and hydrocele repair. There was not personal or family history of haemorrhagic diathesis. The mother of the propositus was a 31 year-old woman with normal menstrual flow, and no haemorrhagic complications during teeth extraction, orthopedic surgery, and caesarian. She told that only an aunt of her mother had a venous thromboembolism episode at the age of 40 . Coagulation screening tests revealed a prolonged thrombin time +10.9 and $+10.1 \mathrm{sec}$ for the propositus and his mother, respectively, and low functional fibrinogen concentration determined by Clauss [26]. Antigenic factor von Willebrand, factor VII, protein C and S, and antithrombin levels were normal. In Table 1 the coagulation screening 
Citation: Marchi R, Rojas H, Echenagucia M, Meyer M, Acosta M, et al. (2014) Fibrinogen Maracaibo: Hypo-Dysfibrinogenemia Caused by a Heterozygous Mutation in the Gen that Encodes for the Fibrinogen Aa Chain (G.1194G>A: P.Gly13>Glu) with Diminished Thrombin Generation. J Blood Disorders Transf 5: 215. doi: 10.4172/2155-9864.1000215

Page 3 of 5

\begin{tabular}{|c|c|c|c|}
\hline & Control & Propositus & Mother \\
\hline $\begin{array}{c}\text { Coagulation test } \\
\text { Prothrombin time (sec) }\end{array}$ & $12-14$ & 16.4 & 16.1 \\
\hline Thrombin time (sec) & $16-19$ & 29.9 & 29.1 \\
\hline aPTT (sec) & $27-35$ & 29.1 & 29.5 \\
\hline Fibrinogen (mg/dL): Clauss & $200-400$ & $80-100$ & $95-111$ \\
\hline $\begin{array}{c}\text { Polimerization } \\
\text { Plasma: } \\
\text { Fibrinogen }(\mathrm{mg} / \mathrm{mL})^{1} \\
\text { Lag time }(\mathrm{sec}) \\
\text { Slope (mOD/sec) } \\
\text { MaxAbs (mOD) } \\
\text { Purified Fibrinogen: } \\
\text { Lag time (sec) } \\
\text { Slope (mOD/sec) } \\
\text { MaxAbs (mOD) }\end{array}$ & $\begin{array}{c}300 \\
15 \\
3.3 \pm 0.7 \\
708 \pm 30 \\
\\
9.1 \pm 7.5 \\
0.386 \pm \\
0.129 \\
90 \pm 23\end{array}$ & $\begin{array}{c}\text { ND } \\
15 \\
1.6 \pm 0.7 \\
743 \pm 11 \\
\text { ND }\end{array}$ & $\begin{array}{c}280 \\
15 \\
1.4 \pm 0.4 \\
785 \pm 17 \\
15^{*} \\
0.183 \pm 0.038^{*} \\
74 \pm 22^{*}\end{array}$ \\
\hline $\begin{array}{c}\text { Permeation } \\
\text { Fibrinogen }(\mathrm{mg} / \mathrm{mL})^{1}\end{array}$ & 280 & 125 & 300 \\
\hline $\mathrm{Ks}\left(\times 10^{-9} \mathrm{~cm}^{2}\right)$ & $\begin{array}{l}8.2 \pm 0.3 \\
\quad(18)\end{array}$ & $\begin{array}{l}9.0 \pm 1.4 \\
(7)\end{array}$ & $\begin{array}{l}5.0 \pm 0.5^{*} \\
(17)\end{array}$ \\
\hline $\begin{array}{l}\text { LSCM } \\
\text { FWHM ( } \mu \mathrm{m})\end{array}$ & $\begin{array}{c}0.58 \pm 0.32 \\
(1220)\end{array}$ & $\begin{array}{l}0.56 \pm 0.31 \\
\quad(1055)\end{array}$ & $\begin{array}{l}0.58 \pm 0.32 \\
\quad(1573)\end{array}$ \\
\hline Density (peaks/ $/ \mu \mathrm{m})$ & $0.457 \pm 0.1$ & $0.367 \pm 0.08^{*+}$ & $0.436 \pm 0.08$ \\
\hline
\end{tabular}

${ }^{1}$ Fibrinogen quantified according reference 20. aPTT: partial activated thromboplastin time; MaxAbs: maximum absorbance. Ks: permeation coefficient or Darcy constant. LSCM: laser scanning microscopy. ND: not done. FWHM: full width at half maximum

* $p<0.05$ compared to control; $+p<0.05$ compared to the propositus' mother

Table 1: Summary of the coagulation screening tests, fibrin polymerization, permeation and laser scanning confocal microscopy studies. Results are reported as mean $( \pm S D)$, and the number of measurements are in brackets.

tests are summarized. DNA analysis revealed a heterozygous missense mutation in the fibrinogen gen that encoded for the Aa chain (FGA g.1194G>A: p.Gly13>Glu) in the propositus and his mother, close to the thrombin cleavage site at Aa Arg16/Gly17. Informed consent was obtained from the propositus' mother. We have named this new hypodysfibrinogenemia as fibrinogen Maracaibo.

\section{Fibrin network characterization}

The patients' fibrin kinetic formation was slower than control. The parameter more affected was the slope (the stage of fibrin fibers formation and association), both in plasma and purified fibrinogen, approximately two times less than control (Figure 1 and Table 1). The permeation coefficient (Ks) of the propositus was similar to control, while that of his mother was approximately 1.6 times less than control $(p<0.05)$. By laser scanning confocal microscopy the patients' fibrin meshwork had normal fibrin morphology (Figure 2).

\section{Haemostasis global tests}

Thromboelastography showed only prolonged INTEM - CT both in the propositus and his mother (Table 2). Interestingly, the propositus had impaired thrombin generation. Peak thrombin and ETP were approximately 3 and 2.5 times less than control (Table 3 ).

\section{Discussion}

In the clinical practice dysfibrinogenemia is suspected when the thrombin time is prolonged and a low ratio between clottable fibrinogen to its antigen is found. However, the ultimate diagnosis is established based on molecular fibrinogen defect tests [27]. A new case of dysfibrinogenemia was found in a venezuelan family with an Aa Gly13> Glu mutation, molecular defect already described in fibrinogen
Olovnice [18] and Krakow II [19], reported as mild bleeders. However, the carriers of fibrinogen Maracaibo were asymptomatic. This mutation was first reported by Gaja et al. [28] in a Czech Republic' family, one carrier had thrombosis and three were asymptomatic.

The $\mathrm{N}$-terminal part of the $\mathrm{A} \alpha$ and $\mathrm{B} \beta$ fibrinogen chains are cleaved by thrombin at Arg 16/Gly17 and Arg14/Gly15, respectively, initiating clot formation. The thrombin - fibrinogen interaction is very specific. The change of glycine, a neutral and small amino acid, by glutamic acid, an acidic and larger one at AaGly13 impairs the substrate binding in the thrombin active site [29], decreasing the efficiency of fibrinopeptides A and B release [18], lengthening clot formation but without affecting clot's morphology, as was observed in fibrinogen Olovnice and Krakow II.

The permeation coefficient or Darcy constant is a measure of the surface available for flow [30]. Under a pressure-driven system the quantity of buffer that percolates through the fibrin clot is quantified as fibrin meshwork porosity. In our experiments, the Ks was not related to fibrinogen molecular defect, since it was normal in the propositus and decreased in his mother. Clots made with plasma are rather a complex system, and it is well known the effects of other plasma proteins in fibrin structure [31,32]. In contrast, in fibrinogen Krakow II the Ks of three family members were consistently increased.

It is important to remark that the fibrin molecules that make up the clots are normal, since FpAs are released. This could explain the almost normal clot morphology. By computer modeling, a lengthening in FpAs release predicts an increase in MaxAbs [33].

By thromboelastography the patients' maximum clot firmness (MCF) was normal. Since clot elastic properties are related to the clot structure, these results confirmed the normality of clot morphology observed by LSCM. Interestingly, the propositus' thrombin generation was decreased. Probably this fact was due to the subject's young age, since it has been reported diminished thrombin generation in childhood [34].

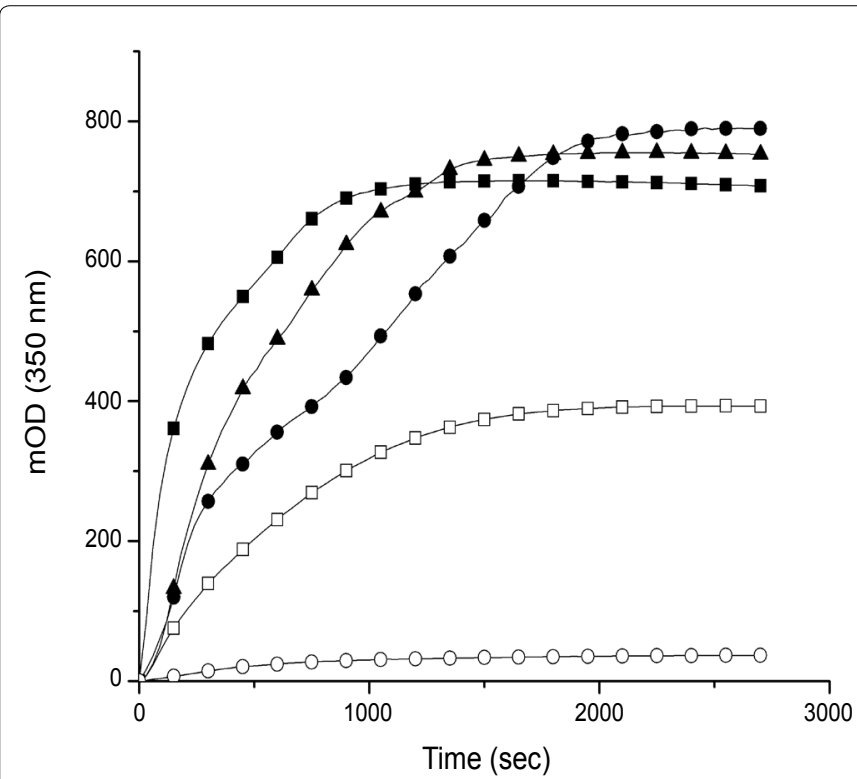

Figure 1: Fibrin polymerization kinetic followed by turbidity at $350 \mathrm{~nm}$. Curves performed with plasma (filled symbol): Control $(\boldsymbol{\square})$, Propositus $(\boldsymbol{\Delta})$, and Propositus' mother $(\bullet)$; and with purified fibrinogen (empty symbol): Control $(\square)$ and Propositus' mother $(O)$. 
Citation: Marchi R, Rojas H, Echenagucia M, Meyer M, Acosta M, et al. (2014) Fibrinogen Maracaibo: Hypo-Dysfibrinogenemia Caused by a Heterozygous Mutation in the Gen that Encodes for the Fibrinogen Aa Chain (G.1194G>A: P.Gly13>Glu) with Diminished Thrombin Generation. J Blood Disorders Transf 5: 215. doi: 10.4172/2155-9864.1000215

Page 4 of 5

In conclusion, the molecular fibrinogen defect Aa Gly13>Glu lengthened fibrin formation but did not alter clot structure. The differences found in thrombin generation between the propositus
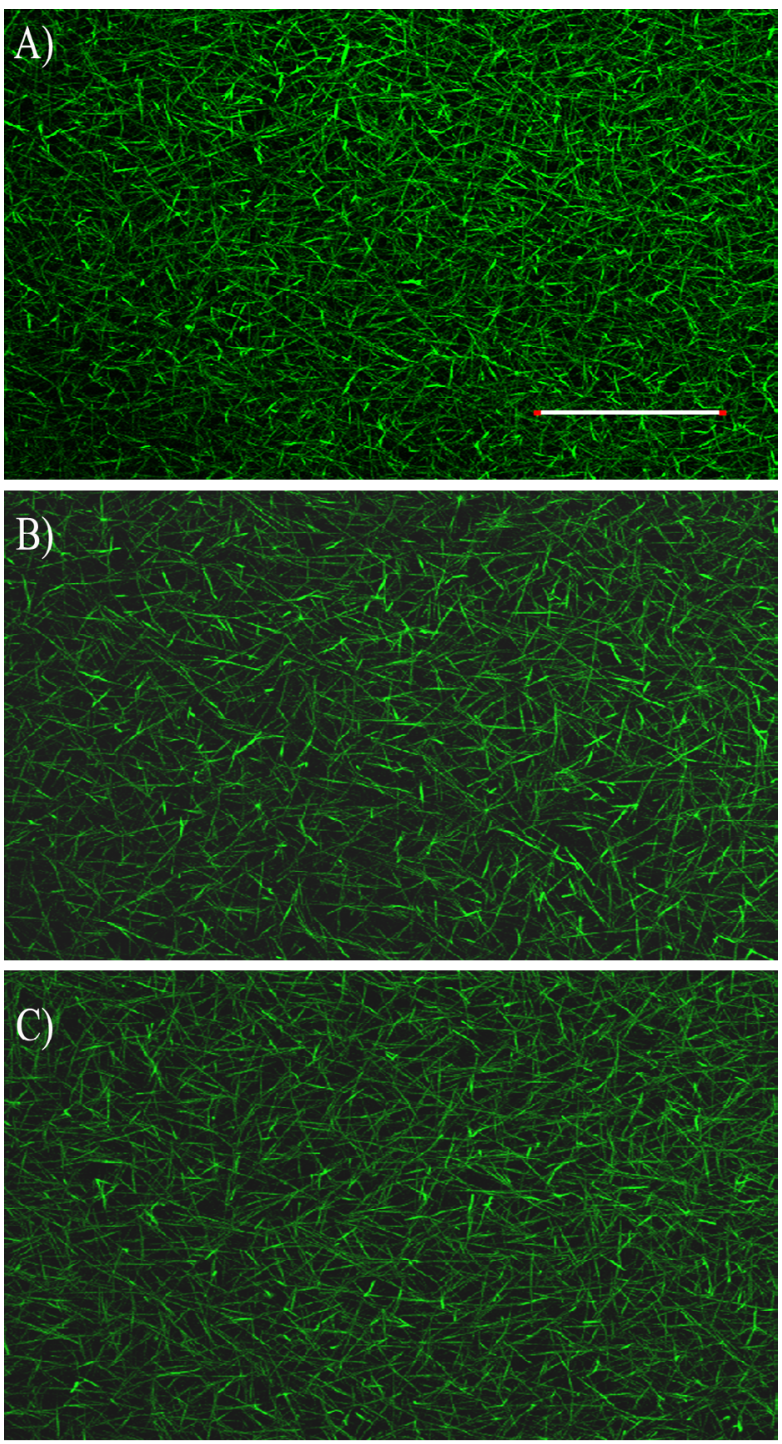

Figure 2: Laser scanning confocal microscopy images of plasma clots. Fibrin is labeled with Alexa 488. Each image was formed from a Z-stack of $30 \mu \mathrm{m}$. a) Control, b) Propositus, and c) Propositus' mother. The magnification bar represents $50 \mu \mathrm{m}$.

\begin{tabular}{|c|c|c|c|}
\hline & Control & Propositus & Mother \\
\hline Lag time $(\min )$ & $3.4 \pm 0.7$ & 6.6 & 3.4 \\
\hline Peak thrombin $(\mathrm{nM})$ & $168 \pm 34$ & 53 & 148 \\
\hline ETP (nM.min) & $786 \pm 110$ & 318 & 974 \\
\hline
\end{tabular}

ETP: Endogenous thrombin potential

Table 3: Calibrated Automated Thrombin Generation (CAT) results. Thrombin formation was triggered by adding $1 \mathrm{pM}$ tissue factor.

and his mother highlights the utility of global assays for therapy individualization.

\section{Acknowledgement}

We want to thank Lic. Marisela De Agrela and Daniela Kanzler for their technical assistance.

\section{References}

1. de Maat MP, Verschuur M (2005) Fibrinogen heterogeneity: inherited and noninherited. Curr Opin Hematol 12: 377-383.

2. Vorjohann S, Fish RJ, Biron-Andréani C, Nagaswami C, Weisel JW, et al (2010) Hypodysfibrinogenaemia due to production of mutant fibrinogen alphachains lacking fibrinopeptide $A$ and polymerisation knob ' $A$ '. Thromb Haemost 104: 990-997.

3. Redman CM, Xia H (2001) Fibrinogen biosynthesis. Assembly, intracellular degradation, and association with lipid synthesis and secretion. Ann N Y Acad Sci 936: 480-495.

4. Mosesson MW (2005) Fibrinogen and fibrin structure and functions. J Thromb Haemost 3: 1894-1904.

5. Vu D, Neerman-Arbez M (2007) Molecular mechanisms accounting for fibrinogen deficiency: from large deletions to intracellular retention of misfolded proteins. J Thromb Haemost 5 Suppl 1: 125-131.

6. http://www.geht.org.

7. http://www.hgmd.cf.ac.uk.

8. Liu CY, Nossel HL, Kaplan KL (1979) The binding of thrombin by fibrin. J Bio Chem 254: 10421-10425.

9. Francis CW, Markham RE Jr, Barlow GH, Florack TM, Dobrzynski DM, et al (1983) Thrombin activity of fibrin thrombi and soluble plasmic derivatives. J Lab Clin Med 102: 220-230.

10. Abramowitz N, Schechter I, Berger A (1967) On the size of the active site in proteases. II. Carboxypeptidase-A. Biochem Biophys Res Commun 29: 862-867.

11. Marsh HC Jr, Meinwald YC, Thannhauser TW, Scheraga HA (1983) Mechanism of action of thrombin on fibrinogen. Kinetic evidence for involvement of aspartic acid at position P10. Biochemistry 22: 4170-4174.

12. Binnie CG, Lord ST (1993) The fibrinogen sequences that interact with thrombin. Blood 81: 3186-3192.

13. Stubbs MT, Oschkinat H, Mayr I, Huber R, Angliker H, et al. (1992) The interaction of thrombin with fibrinogen. A structural basis for its specificity. Eur J Biochem 206: 187-195.

14. Martin PD1, Robertson W, Turk D, Huber R, Bode W, et al. (1992) The structure

\begin{tabular}{|c|c|c|c|c|c|c|c|c|}
\hline & $\begin{array}{c}\text { CT } \\
\text { (sec) }\end{array}$ & $\begin{array}{c}\text { CFT } \\
\text { (sec) }\end{array}$ & $\begin{array}{l}\text { MCF } \\
(\mathrm{mm})\end{array}$ & $\alpha$ angle & $\begin{array}{l}\text { ML } \\
(\%)\end{array}$ & $\begin{array}{c}\text { A10 } \\
(\mathrm{mm})\end{array}$ & $\begin{array}{c}\mathrm{A} 15 \\
(\mathrm{~mm})\end{array}$ & $\begin{array}{c}\mathrm{A} 20 \\
(\mathrm{~mm})\end{array}$ \\
\hline \multicolumn{9}{|l|}{ EXTEM } \\
\hline Reference Values & $38-79$ & $34-159$ & $50-72$ & $63-83$ & $<15$ & $43-65$ & $48-69$ & $50-71$ \\
\hline Propositus & 66 & 54 & 70 & 79 & 8 & 55 & 64 & 67 \\
\hline $\begin{array}{l}\text { Propositus' mother } \\
\text { INTEM }\end{array}$ & 52 & 59 & 75 & 78 & - & 57 & 67 & 71 \\
\hline $\begin{array}{l}\text { Reference Values } \\
\text { Propositus } \\
\text { Propositus' mother }\end{array}$ & $\begin{array}{c}100-173 \\
275 \\
223\end{array}$ & $\begin{array}{c}34-108 \\
120 \\
76\end{array}$ & $\begin{array}{c}50-72 \\
69 \\
77\end{array}$ & $\begin{array}{c}70-83 \\
68 \\
75\end{array}$ & $\begin{array}{c}<15 \\
2 \\
-\end{array}$ & $\begin{array}{c}44-66 \\
44 \\
51\end{array}$ & $\begin{array}{c}48-69 \\
57 \\
63\end{array}$ & $\begin{array}{c}50-71 \\
63 \\
68\end{array}$ \\
\hline
\end{tabular}

EXTEM: extrinsic activator thromboelastometry; INTEM: intrinsic activator thromboelastometry; CT: clotting time; CFT: Clot formation time; MCF: maximum clot firmness; A10, A15, A20: clot firmness (amplitude) after 10, 15 and 20 min

Table 2: Thromboelastographic results performed using whole blood, the extrinsic and intrinsic coagulation pathway were analyzed. 
Citation: Marchi R, Rojas H, Echenagucia M, Meyer M, Acosta M, et al. (2014) Fibrinogen Maracaibo: Hypo-Dysfibrinogenemia Caused by a Heterozygous Mutation in the Gen that Encodes for the Fibrinogen Aa Chain (G.1194G>A: P.Gly13>Glu) with Diminished Thrombin Generation. J Blood Disorders Transf 5: 215. doi: 10.4172/2155-9864.1000215

Page 5 of 5

of residues 7-16 of the A alpha-chain of human fibrinogen bound to bovine thrombin at 2.3-A resolution. J Biol Chem 267: 7911-7920.

15. Denninger MH, Finlayson JS, Reamer LA, Parquet-Gernez A, Goudemand M et al. (1978) Congenital dysfibrinogenemia: fibrinogen Lille. Thromb Res 13: 453-466

16. Meyer M, Kutscher G, Stürzebecher J, Riesener G, Lutze G (2003) Fibrinogen Magdeburg I: a novel variant of human fibrinogen with an amino acid exchange in the fibrinopeptide A (Aalpha 9, Leu-->Pro). Thromb Res 109: 145-151.

17. Niwa K, Yaginuma A, Nakanishi M, Wada Y, Sugo T, et al. (1993) Fibrinogen Mitaka II: a hereditary dysfibrinogen with defective thrombin binding caused by an A alpha Glu-11 to Gly substitution. Blood 82: 3658-3663.

18. Kotlín R, Zichová K, Suttnar J, Reicheltová Z, Salaj P, et al. (2011) Congenital dysfibrinogenemia Al̂t Gly13Glu associated with bleeding during pregnancy. Thromb Res 127: 277-278.

19. Pietrys D, Balwierz W, Iwaniec T, Vorjohann S, Neerman-Arbez M, et al. (2011) Two different fibrinogen gene mutations associated with bleeding in the same family (A ÎtGly13Glu and $\hat{I}^{3} \mathrm{Gly} 16 \mathrm{Ser}$ ) and their impact on fibrin clot properties: fibrinogen Krakow II and Krakow III. Thromb Haemost 106: 558-560.

20. INGRAM IC (1952) The determination of plasma fibrinogen by the clot-weight method. Biochem J 51: 583-585.

21. Jacobsen E, Kierulf $P$ (1973) A modified beta-alanine precipitation procedure to prepare fibrinogen free of antithrombin III and plasminogen. Thromb Res 3 : $145-148$

22. Marchi R, Rojas H, Meyer M, Castillo O, De Sáez Ruiz A, et al. (2011) A novel missense mutation in the FGB g. $3354 \mathrm{~T}>\mathrm{A}(\mathrm{p}$. Y41N), fibrinogen Caracas VIII. Thromb Haemost 105: 627-634.

23. Blombäck B, Okada M (1982) Fibrin gel structure and clotting time. Thromb Res 25: 51-70.
24. Marchi R, Rojas H (2013) Confocal microscopy as useful tool for studying fibrincell interactions. https://intechopencom.

25. Nijhuis S, Apitz CR, Hemker H (2009) Thrombin generation in a thin layer of whole blood [Abstract]. J Thromb Haemost 7: http://www. blackwellpublishing com/isth2009/abstract.

26. CLAUSS A (1957) [Rapid physiological coagulation method in determination of fibrinogen]. Acta Haematol 17: 237-246

27. Cunningham MT, Brandt JT, Laposata M, Olson JD (2002) Laboratory diagnosis of dysfibrinogenemia. Arch Pathol Lab Med 126: 499-505.

28. Gaja A TF, Okumuna N (2001) Hereditární dysfibrinogenemies Aa13Gly®Glu mutací. In: Malý M, Pecka J, editors Trombóza a hemostáza HK Credit: HradecKrálové. p. 114.

29. Rose T, Di Cera E (2002) Three-dimensional modeling of thrombin-fibrinogen interaction. J Biol Chem 277: 18875-18880.

30. Blombäck B, Okada M (1982) On pores in fibrin gels. Thromb Res 26: 141-142.

31. Nair CH, Dhall DP (1991) Studies on fibrin network structure: the effect of some plasma proteins. Thromb Res 61: 315-325.

32. Shah GA, Nair CH, Dhall DP (1987) Comparison of fibrin networks in plasma and fibrinogen solution. Thromb Res 45: 257-264.

33. Weisel JW, Nagaswami C (1992) Computer modeling of fibrin polymerization kinetics correlated with electron microscope and turbidity observations: clot structure and assembly are kinetically controlled. Biophys J 63: 111-128.

34. Andrew M, Paes B, Johnston M (1990) Development of the hemostatic system in the neonate and young infant. Am J Pediatr Hematol Oncol 12: 95-104.
Citation: Marchi R, Rojas H, Echenagucia M, Meyer M, Acosta M, et al. (2014) Fibrinogen Maracaibo: Hypo-Dysfibrinogenemia Caused by a Heterozygous Mutation in the Gen that Encodes for the Fibrinogen Aa Chain (G.1194G>A: P.Gly13>Glu) with Diminished Thrombin Generation. J Blood Disorders Transf 5: 215. doi: 10.4172/2155-9864.1000215 